\title{
Expression of Multiple Gap Junction Proteins in Human Fetal and Infant Hearts
}

\author{
SU-CHIUNG CHEN, LLOYD M. DAVIS, EILEEN M. WESTPHALE, ERIC C. BEYER, \\ AND JEFFREY E. SAFFITZ
}

\author{
Departments of Pathology [J.E.S.], Medicine [J.E.S.], and Pediatrics [L.M.D., E.M.W., \\ E.C.B.], Washington University School of Medicine, and Department of Pediatrics [S.C.], \\ St. Louis University School of Medicine, St. Louis, Missouri 63110
}

\section{ABSTRACT}

Mammalian cardiac myocytes express multiple gap junction channel proteins or connexins. Expression patterns of the avian homologues of the mammalian cardiac connexins change during cardiac morphogenesis in association with changes in the electrophysiologic properties of intercellular junctions in chick cardiac myocytes. To determine whether expression of cardiac connexins is developmentally regulated in humans, we characterized connexin mRNA and protein content and distribution in hearts of 11 human fetuses (74 to $122 \mathrm{~d}$ gestational age), seven children ( 0.5 mo to $3 \mathrm{y}$ of age), and two adults. Northern blot analysis identified transcripts of connexin40 (Cx40), connexin43 (Cx43), and connexin45 (Cx45) genes in all hearts analyzed. Cx40 mRNA was approximately 5-fold more abundant in samples from fetal hearts than in hearts of children or adults. However, fetal samples used for RNA extraction included atrial as well as ventricular myocardium, whereas samples from children and adults were exclusively ventricular. Northern analysis of adult human right atrial appendages revealed abundant Cx40 mRNA, thus suggesting that the greater amount of $\mathrm{Cx} 40$ signal seen on Northern blots from fetal hearts could have been attributable to atrial contributions. Neither $\mathrm{Cx} 43$ nor $\mathrm{Cx} 45$ mRNA varied significantly in amount in samples from the different developmental stages analyzed. Immunofluorescence identified abundant $\mathrm{Cx} 43$ in the known distribution of gap junctions in myocytes in sections of all hearts. Cx45 staining was inconspicuous in fetal hearts but was readily apparent in cardiac myocytes in hearts of older subjects. In contrast, $\mathrm{Cx} 40$ staining in the ventricle was confined to mural coronary arteries, apparently in endothelial cells, whereas in the atrium Cx40 staining at myocyte junctions was abundant. Junctions in hypertrophied myocardium of children with congenital or acquired heart disease appeared more prominent and complex than in normal tissues. Thus, the human heart contains multiple connexins, but their distribution and developmental patterns differ from each other and from those in other species. Cx45 expression is not restricted to the fetal human heart. Cx40 expression in ventricles occurs selectively in coronary arteries. (Pediatr Res 36: 561-566, 1994)

Cx40, connexin 40

Cx43, connexin 43

Cx45, connexin 45

pS, picoSiemen

\section{Abbreviations}

and the nodes and bundles of the cardiac conduction system may be attributable, in part, to different patterns of connexin expression.

Expression of the avian homologues of these connexins changes during chick cardiac morphogenesis (9). Expression of $\mathrm{Cx} 45$ appears to be highly regulated during embryonic development in chicks. CX45 mRNA is abundant in hearts from 6-d-old chick embryos but is much less abundant in later developmental stages and is expressed minimally in the adult chicken heart (9). Recordings of gap junction channels expressed in communication-deficient cells transfected individually with the three cardiac connexins revealed distinct biophysical properties including unitary conductances and voltage dependence (2). For example, mammalian $\mathrm{Cx} 40$ and its chick
Received February 1, 1994; accepted May 27, 1994.

Correspondence and reprint requests: Jeffrey E. Saffitz, M.D., Ph.D., Department of Pathology, Box 8118, Washington University School of Medicine, $660 \mathrm{~S}$ Euclid Ave., St. Louis, MO 63110.

Supported by National Institutes of Health Grants HL45466, HL17647, and HL36773.

${ }^{1}$ E.C.B. is an Established Investigator of the American Heart Association. 
homologue, $\mathrm{Cx} 42$, form channels with large unitary conductances (predominately 121 or $158 \mathrm{pS})(2,10,11)$, whereas channels made by $\mathrm{Cx} 43$ have a predominant unitary conductance of $44 \mathrm{pS}$ (2). Cx45 channels have unitary conductances of only approximately $30 \mathrm{pS}$ (2). These observations suggest that junctional conductance in cardiac myocytes that express multiple connexins depends, in part, on the relative abundance of channels formed by each of the three proteins. This hypothesis is supported by observations that the electrophysiologic properties of intercellular junctions in chick cardiac myocytes change during development in a pattern consistent with the known changes in connexin phenotype expression (2). There have been some descriptions of changes in expression of Cx43 mRNA and protein in the developing rodent heart (12-14). However, neither $\mathrm{Cx} 40$ nor $\mathrm{Cx} 45$ has been examined in the developing mammalian heart.

Expression of cardiac connexins in human fetal and infant myocardium has not been characterized previously, nor have the effects of myocardial disease on connexin expression been fully explored. Moreover, considerable species variation may exist in connexin expression patterns (3-8). Thus, observations in chick and rodent hearts may not be applicable to human myocardium. Accordingly, the present study was performed to characterize expression of cardiac connexins in human fetal and infant hearts and to determine whether expression of cardiac connexins is developmentally regulated or altered in myocardial disease.

\section{METHODS}

Tissue acquisition. Myocardial samples from 20 human hearts were analyzed. These included samples from 11 fetuses ( 74 to $122 \mathrm{~d}$ gestational age), seven children $(0.5$ mo to $3 \mathrm{y}$ of age), and two adults. Fetal hearts were obtained from the Central Laboratory for Human Embryology at the University of Washington, Seattle, in accordance with U. S. Public Health Service guidelines on research using human fetal tissue. These cardiac samples were collected from conceptal tissues, snap frozen, and shipped to our laboratory on dry ice. Upon arrival, a small fragment of the left ventricle was removed from the frozen sample and stored at $-70^{\circ} \mathrm{C}$ for subsequent preparation of frozen sections and immunofluorescence analysis. The remainder of the sample was divided into two approximately equal portions, and each was subsequently used for preparation of total tissue RNA and Northern blot analysis. Although the bulk of the frozen fetal cardiac samples consisted of right and left ventricular myocardium, the atria were also unavoidably included in the samples used for preparation of total tissue RNA.

The infant myocardial samples were obtained from patients undergoing cardiac surgery at St. Louis Children's Hospital and included three left ventricular samples from patients with hypoplastic left heart syndrome who underwent cardiac transplantation, one right ven- tricular sample from a patient who underwent repair of tetralogy of Fallot, and a sample of left ventricle obtained from a cardiac allograft that was excised from a 1-y-old patient at the time of retransplantation because of acute rejection. Samples of left ventricular myocardium were also obtained at autopsy within $2 \mathrm{~h}$ of death in a 5-mo-old child who died of idiopathic dilated cardiomyopathy and a 3-y-old normal child who died of head injury sustained in a motor vehicle accident. Adult left ventricular samples were obtained from a 38-y-old patient with dilated cardiomyopathy who was undergoing heart transplantation and a 33-y-old trauma victim with no history of heart disease. All of the left ventricular samples from pediatric and adult hearts were divided into multiple portions, frozen rapidly, and stored at $-70^{\circ} \mathrm{C}$ until used in immunofluorescence and Northern blot analyses.

Northern blot analysis. Total cellular RNA was prepared from the combined atrial and ventricular myocardium of fetal hearts and ventricular myocardium of pediatric and adult hearts using the guanidinium isothiocyanatephenol-chloroform extraction method (15) as previously described (1). An additional study was performed to compare the relative abundance of $\mathrm{Cx} 40$ transcripts in RNA isolated from the right atrial appendage and left ventricle of two other adults (aged 54 and $66 \mathrm{y}$ ). Each lane was loaded with $10 \mu \mathrm{g}$ of RNA except for the membrane probed with $\mathrm{Cx} 45$, in which each lane contained $20 \mu \mathrm{g}$ of RNA. The amount of RNA transferred to each lane of the nylon membranes was determined by visual assessment under UV light of gels and membranes stained with ethidium bromide. Approximately equal amounts of RNA were loaded and transferred as judged by this criterion.

Membranes containing RNA from fetal, pediatric, and adult hearts were hybridized with ${ }^{32} \mathrm{P}$-labeled DNA probes corresponding to human $\mathrm{Cx} 40$, rat $\mathrm{Cx} 43$, or human Cx45 as previously described (16). Human Cx43 has been cloned and sequenced, and it shares more than $97 \%$ amino acid sequence homology to rat $\mathrm{Cx} 43(16,17)$. In previous studies, we have found that the ${ }^{32} \mathrm{P}$-labeled DNA probes hybridize specifically under stringent conditions with their respective mRNA obtained from human myocardium (16).

Probes were labeled with ${ }^{32} \mathrm{P}$ using random hexanucleotide primers and the Klenow fragment of DNA polymerase $I$ as described (1). Standard hybridization conditions with stringent washes were used for all blots. Positive Northern blot analyses were confirmed in two additional experiments by repeated hybridization of the same DNA probes with RNA isolated from additional tissue samples that were available. The relative abundance of Cx mRNA among samples was determined for each connexin by densitometric analysis of bands in the Northern blots.

Anticonnexin antibodies. Cx43 was detected with a mouse monoclonal $\operatorname{IgG}$ antibody raised against amino acids 252-270 of rat Cx43 (Chemicon International Inc., Temecula, CA). Cx 40 was detected using affinity-purified polyclonal rabbit antibodies raised against residues 316- 
329 of dog Cx40. Cx45 was detected using affinity-purified rabbit polyclonal antibodies raised against residues 285-298 of dog/human Cx45. We have described previously the preparation and characterization of these monospecific antibodies $(1,18,19)$. In brief, their specificity and absence of cross-reactivity were demonstrated by inhibition of immunostaining by preincubation of antibodies with their corresponding peptide immunogens, by immunoprecipitation experiments in which the Cx40 and $\mathrm{Cx} 45$ antibodies (and a $\mathrm{Cx} 43$ polyclonal antiserum that was raised against a peptide of 20 amino acids including the 19 used for the Cx43 MAb) precipitated only the relevant connexin, and by confirmation by electron microscopy that these antibodies bind only to gap junctions rather than to other membrane structures.

In previous studies of adult human myocardium (16), we observed binding of these antibodies to frozen sections of atrial and ventricular cardiac myocytes in a pattern consistent with the known distribution of gap junctions.

Immunocytochemistry. Frozen sections of fetal, pediatric, and adult myocardium were prepared at a thickness of $12 \mu \mathrm{m}$, mounted on gelatin-coated slides, fixed in $1 \%$ paraformaldehyde, permeabilized with $1 \%$ Triton X-100, and, after being washed in PBS, preincubated for $30 \mathrm{~min}$ in blocking buffer composed of 3\% normal goat serum, $0.4 \%$ nonfat dry milk, $2 \%$ IgG-free BSA (Sigma Chemical Co., St. Louis, MO), and 0.3\% Triton X-100 in PBS. Sections were incubated overnight with the respective primary antibodies diluted 1:400 in blocking buffer. Nonimmune mouse serum or nonimmune rabbit serum was used as a negative control. After washing in PBS, sections were incubated with a 1:800 dilution of the appropriate rabbit or mouse secondary antibody conjugated to CY3 (Jackson Immunoresearch Laboratories, West Grove, PA) or a 1:200 dilution of secondary antibodies conjugated to FITC (Boehringer-Mannheim, Indianapolis, IN). Sections were examined by conventional epifluoresence microscopy with filter sets appropriate for the specific fluorochromes.

\section{RESULTS}

Northern blot analyses. mRNA for $\mathrm{Cx} 40, \mathrm{Cx} 43$, and $\mathrm{Cx} 45$ were detected in human myocardium. A representative Northern blot showing results obtained from hybridizing RNA isolated from fetal, pediatric, and adult hearts is shown in Figure 1. Cx43 transcripts were abundant in all samples from the earliest fetal heart to the adult hearts. Densitometry demonstrated less than 50\% variation between the $\mathrm{Cx} 43$ signal in the adult samples and samples from any of the other age groups. Cx40 transcripts were also detected in all samples. Densitometry revealed an approximately 5 -fold greater signal in fetal hearts compared with samples from children and adults. In contrast to the Northern blot hybridization observed with $\mathrm{Cx} 43$ and $\mathrm{Cx} 40$ probes, the $\mathrm{Cx} 45$ bands were weak even when twice as much total RNA was

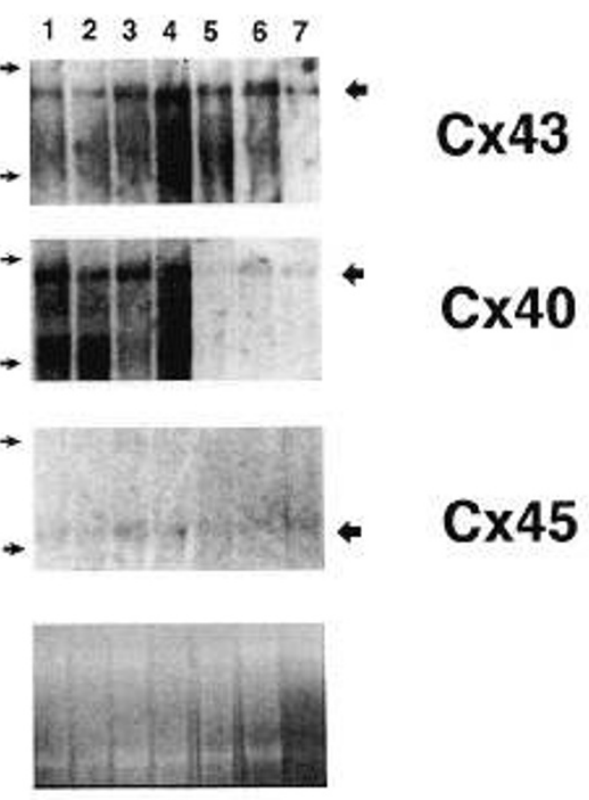

Figure 1. Northern blots of total RNA derived from representative fetal (lanes 1-4), pediatric (lanes 5 and 6), and adult (lane 7) hearts. RNA was prepared from combined atrial and ventricular myocardium of fetuses. Remaining RNA was prepared from left ventricular samples of the explanted heart of a 1-mo-old cardiac allograft recipient with hypoplastic left ventricle, a 3-y-old normal child, and a 38-y-old normal adult. Small arrows indicate the positions of $18 \mathrm{~S}$ and $28 \mathrm{~S}$ rRNA and the large arrows show the connexin mRNA bands. The lower panel shows ethidium bromide staining of the $\mathrm{Cx} 45$ blot and indicates that approximately equal amounts of total RNA were loaded in each lane. Similar loading equivalences were observed in ethidium bromide-stained gels for the other connexins.

loaded on the gel that was ultimately analyzed. There appeared to be no selective expression of Cx45 in human fetal myocardium, inasmuch as the amounts of $\mathrm{Cx} 45$ mRNA detected in samples from 74- and 76-d-old fetal hearts did not differ significantly from that observed in RNA derived from the left ventricle of a 38 -y-old normal adult heart.

Immunofluorescence analysis. $\mathrm{Cx} 43$ immunoreactivity was readily detected in all samples (Fig. 2). Cx43 immunostaining was observed in the distribution of intercalated disks. In general, the intercellular junctions appeared to be more prominent and more complex in the hypertrophied myocardium of children with congenital or acquired heart disease. However, a detailed morphometric study was not performed, and no specific quantitative conclusions can be reached. Cx45 immunostaining was inconspicuous in fetal hearts but readily apparent in the hearts of children and adults (Fig. 2). In contrast to the distinctive myocardial staining patterns seen with $\mathrm{Cx} 43$ and $\mathrm{Cx} 45$, the distribution of Cx40 immunoreactivity in ventricular tissues was confined to endothelial regions of small- and medium-sized mural coronary arteries (Fig. 3). Little or no Cx40 immunoreactivity was detected at intercalated disks in ventricular myocardium from fetal, infant, and adult hearts.

As indicated previously, RNA used in Northern blots was extracted from combined ventricular and atrial myo- 

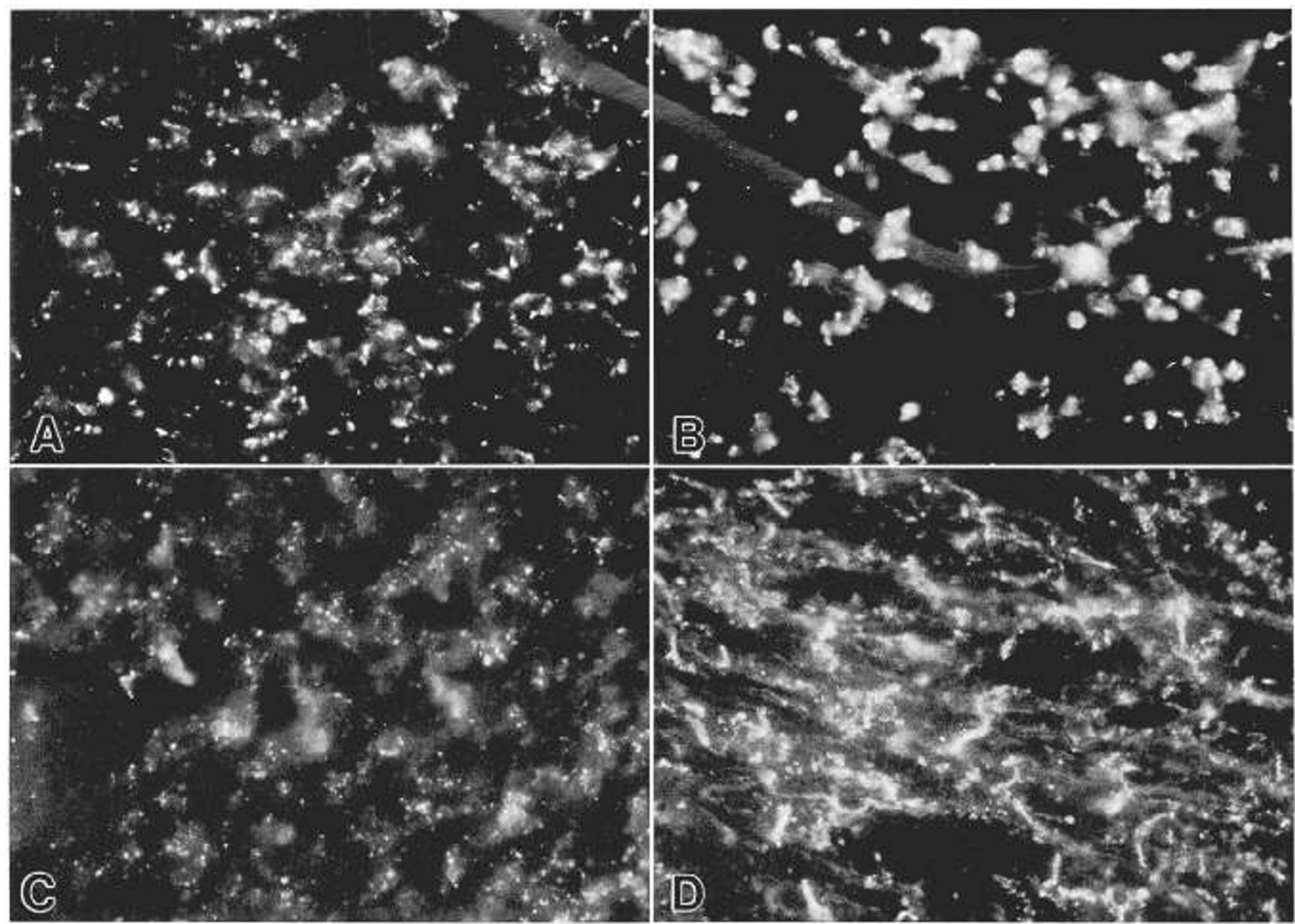

Figure 2. Representative immunofluorescence preparations showing connexin expression in human fetal and pediatric hearts. $A$, Cx43 immunoreactivity in the ventricle of a 78-d-old fetal heart. $B, \mathrm{Cx} 43$ immunofluorescence in a 0.5 -mo-old infant left ventricle from an explanted heart with hypoplastic left heart syndrome. $C, \mathrm{Cx} 45$ immunoreactivity in the explanted left ventricle of a 1-mo-old cardiac transplant recipient with hypoplastic left heart syndrome. $D, C x 45$ immunofluorescence in the left ventricle from a 3-y-old normal patient. Original magnification $\times 400$.

cardium from fetal hearts but only from ventricular tissue in hearts of children and adults. As shown in Figure 1, more abundant $\mathrm{Cx} 40$ transcript levels were detected in the fetal samples. However, because immunohistochemical studies revealed $\mathrm{Cx} 40$ staining only within vessels in both fetal and adult ventricular myocardium, additional experiments were performed to determine whether human atrial myocardium selectively expresses high levels of Cx40 transcripts. Figure 4 compares the results of Northern blots of RNA extracted from the right atrial appendage myocardium obtained from the normal heart of a 66-y-old organ donor. A distinct $\mathrm{Cx} 40$ signal was detected in atrial samples after an exposure interval insufficient to produce a detectable Cx40 signal in ventricular tissue. Immunofluoresence microscopy of sections prepared from the right atrial appendage revealed prominent $\mathrm{Cx} 40$ staining at regions of intercellular junctions (Fig. 4). Cx40 immunoreactivity was also detected in sections prepared from a minute sample obtained from the right atriotomy site in a 5-mo-old male who underwent surgical repair of tetralogy of Fallot (data not shown). Thus, $\mathrm{Cx} 40 \mathrm{mRNA}$ and protein expression are much greater in human atrial myocardium than in the ventricle.

\section{DISCUSSION}

The results of these studies indicate that three distinct connexins are expressed in the human heart. Cx43 appears to be the predominant gap junction protein in human ventricular myocardium and was detected abundantly by immunofluorescence analysis in all samples. Cx45 protein expression was more apparent by immunofluorescence in the hearts of children and adults than in fetal hearts. However, the junctions in fetal hearts are very small. Therefore, it is possible that $\mathrm{Cx} 45$ expression in fetal hearts was roughly equivalent to that in the older hearts but appeared to be less abundant because of the structural differences in the intercellular junctions in fetal and pediatric hearts. Nevertheless, the combined results of Northern blot analysis and immunofluorescence indicate that neither $\mathrm{Cx} 45$ nor $\mathrm{Cx} 43$ is selectively expressed in the fetal heart over the developmental intervals studied. Previous studies in the developing chick heart (9) 

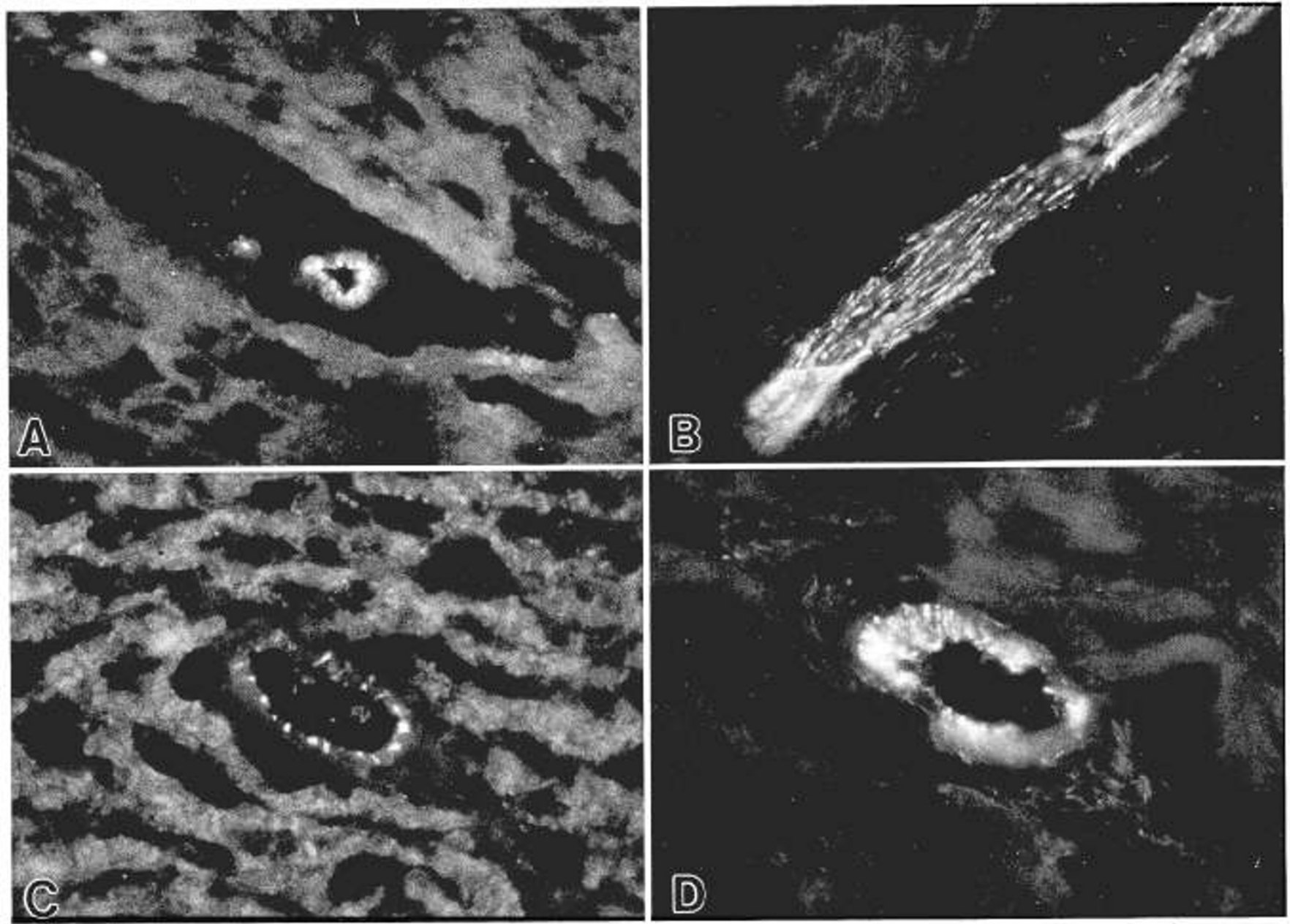

Figure 3. Representative immunofluorescence preparations showing $\mathrm{Cx} 40$ immunoreactivity confined to small and medium intramural coronary arteries. In all cases, immunofluorescence signal appears to be localized to intercellular junctions of endothelial cells. $A$, left ventricle from 105-d-old fetal heart; $B$, left ventricle from 5-mo-old child with dilated cardiomyopathy; $C$, right ventricular sample from a 4-mo-old child who underwent repair of tetralogy of Fallot; $D$, left ventricle from a 3-y-old child with a normal heart. Panels $A, C$, and $D$ show vessels cut in cross section, whereas panel $B$ shows a vessel cut in a longitudinal plane in which a portion of the vessel wall has been cut away showing the endothelial lining below. Original magnification $\times 400$.

demonstrated enhanced $\mathrm{Cx} 45$ expression in d-6 embryos, a developmental stage roughly equivalent to a d-35 human embryo. Cx45 expression decreased significantly on developing chick hearts at late stages of development. Thus, it is possible that there may have been enhanced expression of $\mathrm{Cx} 45$ or other connexins in younger human fetal hearts undergoing early cardiac morphogenic events. However, we were unable to analyze connexin expression in fetal hearts younger than $74 \mathrm{~d}$ of gestational age.

Northern blots demonstrated approximately 5-fold greater expression of $\mathrm{Cx} 40$ transcripts in fetal hearts than in hearts of children or adults. However, the inclusion of atrial tissues in the fetal samples and the demonstration of Cx40 mRNA and protein expression in human atrial myocardium suggests that some, if not most, of the apparent increase in Cx40 expression in fetal hearts seen with Northern blot analysis was attributable to the atrial contribution. Another potential source of $\mathrm{Cx} 40$ transcript is the Purkinje fiber network of the ventricular conduction system. We (6) and others (20-23) have found ex- pression of $\mathrm{Cx} 40$ to a greater extent in Purkinje fibers than ventricular myocardium. It is likely that much of the cardiac conduction system was included in the fetal samples used in Northern analysis, whereas the pediatric and adult samples did not include significant components of the conduction system. We did not specifically identify conduction tissue in the fetal heart sections analyzed by immunofluorescence microscopy, and therefore we do not know whether Cx40 is selectively expressed in the human fetal conduction system. Nevertheless; the possibility remains that some of the enhanced $\mathrm{Cx} 40$ transcript expression observed in fetal hearts could have been derived from conduction system components. Additional studies of connexin expression in the conduction system during development are required to elucidate this question.

A striking disparity was observed in the distribution of $\mathrm{Cx} 40$ protein in comparison with $\mathrm{Cx} 43$ and $\mathrm{Cx} 45$ proteins in human left ventricular myocardium. $\mathrm{Cx} 43$ and $\mathrm{Cx} 45$ immunoreactivity were distributed in a characteristic pattern consistent with the known distribution of gap junc- 


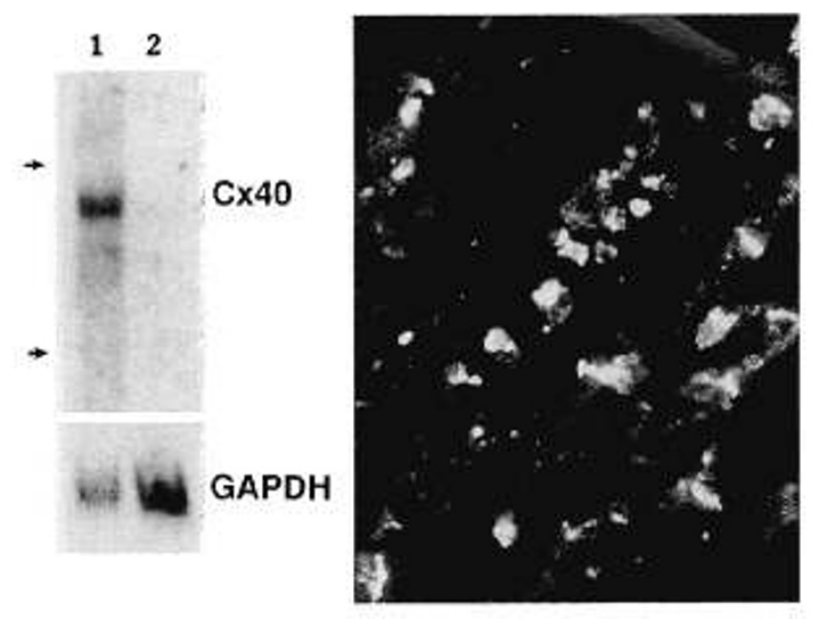

Figure 4. Left, Northern blots of total cellular RNA derived from the right atrial appendage (lane 1 ) and the anterior left ventricle (lane 2) of a 66-y-old man whose normal heart was donated for harvesting valve allografts. RNA was hybridized with a probe for human $C \times 40$. An intense signal was detected in the atrial sample under exposure conditions insufficient to lead to formation of a significant ventricular signal. The blots were also hybridized with a probe for glyceraldehyde-3phosphate dehydrogenase $(G A P D H)$ to control for loading conditions. The small arrows indicate the positions of $18 \mathrm{~S}$ and $28 \mathrm{~S}$ rRNA. Right, Immunofluorescence preparation of a section of right atrial appendage from a 54-y-old normal organ donor. Bright $\mathrm{Cx} 40$ immunoreactivity in the known distribution of gap junctions is apparent in myocytes cut in both long and transverse planes of section. Original magnification $\times 400$.

tions interconnecting cardiac myocytes. However, Cx40 immunoreactivity in the left ventricle was detected only in small and medium intramural coronary vessels in a pattern that was strongly suggestive of staining of intercellular junctions of endothelial cells. Of course, these results do not exclude the possibility of low levels of $\mathrm{Cx} 40$ protein expression in myocyte gap junctions. However, intense immunostaining of $\mathrm{Cx} 40$ was apparent only in the vascular sites. Previous studies in canine myocardium have established that $\mathrm{Cx} 40$ is expressed in myocyte junctions of the left ventricle $(1,6)$. Previous studies of avian and rodent hearts have also demonstrated $\mathrm{Cx} 40$ immunoreactivity in the endothelium of intramural coronary vessels (20-24). Thus, the results of the present study suggest a different tissue distribution of $\mathrm{Cx} 40$ expression in human as opposed to some other mammalian species.

The role of intercellular communication at myocyte gap junctions in mediating cardiac morphogenesis and its potential pathogenetic influence in congenital heart disease are still unknown. However, it is now clear that mammalian cardiac myocytes express multiple connexins that form channels with distinct biophysical properties $(1,2,19)$ and that different cardiac tissues such as atrial and ventricular myocardium and the nodes and bundles of the conduction system express different combinations of connexins (20-25). Thus, it seems likely that connexin expression patterns confer specific functional properties of cardiac tissues that may ultimately be important in the development of the heart. The use of transgenic and targeted gene disruption strategies in future studies may shed light on these roles.
Acknowledgments. The authors thank Karen Green for technical assistance; Walter Clermont for photographic assistance; James Grant, M.D., for pediatric heart tissues; and Susan Johnson for secretarial assistance.

\section{REFERENCES}

1. Kanter HL, Saffitz JE, Beyer EC 1992 Cardiac myocytes express multiple gap junction proteins. Circ Res 70:438-444

2. Veenstra RD, Wang H-Z, Westphale EM, Beyer EC 1992 Multiple connexins confer distinct regulatory and conductance properties of gap junctions in developing heart. Circ Res 71:1277-1283

3. Van Kempen MJA, Fromaget C, Gros D, Moorman AFM, Lamers WH 1991 Spatial distribution of connexin 43, the major cardiac gap junction protein, in the developing and adult rat heart. Circ Res 68:1638-1651

4. Anumonwo JMB, Wang H-Z, Trabka-Janik E, Dunham B, Veenstra RD, Delmar M, Jalife J 1992 Gap junctional channels in adult mammalian sinus nodal cells: immunolocalization and electrophysiology. Circ Res 71:229-239

5. Gourdie R, Green C, Severs N, Thompson R 1992 Immunolabelling patterns of gap junction connexins in the developing and mature rat heart. Anat Embryol 185:363-378

6. Kanter HL, Laing JG, Beau SL, Beyer EC, Saffitz JE 1993 Distinct patterns of connexin expression in canine Purkinje fibers and ventricular muscle. Circ Res 72:1124-1131

7. Oosthoek PW, Viragh S, Mayen AEM, Van Kempen MJA, Lamers WH, Moorman AFM 1993 Immunohistochemical delineation of the conduction system. I. The sinoatrial node. Circ Res 73:473-481

8. Oosthoek PW, Viragh S, Lamers WH, Moorman AFM 1993 Immunohistochemical delineation of the conduction system. II. The atrioventricular node and the Purkinje fibers. Circ Res 73:482-491

9. Beyer EC 1990 Molecular cloning and developmental expression of two chick embryo gap junction proteins. J Biol Chem 265:14439-14443

10. Fishman GI, Spray DC, Leinwand LA 1990 Molecular characterization and functional expression of the human cardiac gap junction channel. J Cell Biol 111:589-598

11. Veenstra RD, Beblo DA, Wang H-Z, Westphale EM, Beyer EC 1993 Unique ionic conductance and selectivity of connexin 40 channels, a major gap junction protein in conducting tissues. Circ 88:I-175(abstr)

12. Fromaget C, el Aoumari A, Dupont E, Briand JP, Gros D 1990 Changes in the expression of connexin 43 , a cardiac gap junctional protein, during mouse heart development. J Mol Cell Cardiol 22:1245-1258

13. Fishman GI, Hertzberg EL, Spray DC, Leinwand LA 1991 Expression of connexin43 in the developing rat heart. Circ Res 68:782-787

14. Ruangvoravat CP, Lo CW 1992 Connexin 43 expression in the mouse embryo: localization of transcripts within developmentally significant domains. Dev Dyn 194:261-281

15. Chomczynski P, Sacchi N 1987 Single-step method of RNA isolation by acid guanidinium thiocyanate-phenol-chloroform extraction. Anal Biochem 162:156-159

16. Kanter HL, Saffitz JE, Beyer EC 1994 Molecular cloning of two human cardiac gap junction proteins, connexin 40 and connexin45. $\mathrm{J} \mathrm{Mol}$ Cell Cardiol 26:861-868

17. Beyer EC, Paul DL, Goodenough DA 1987 Connexin43: a protein from rat heart homologous to a gap junction protein from liver. J Cell Biol 105:26212629

18. Beyer EC, Kistler J, Paul DL, Goodenough DA 1989 Antisera directed against connexin 43 peptides react with a $43 \mathrm{kD}$ protein localized to gap junctions in myocardium and other tissues. J Cell Biol 108:595-605

19. Kanter HL, Laing JG, Beyer EC, Green KG, Saffitz JE 1993 Multiple connexins colocalize in canine ventricular myocyte gap junctions. Circ Res 73:344-350

20. Gourdie RG, Green CR, Severs NJ, Anderson RH, Thompson RP 1993 Evidence for a distinct gap-junctional phenotype in ventricular conduction tissues of the developing and mature avian heart. Circ Res 72:278-289

21. Gourdie RG, Severs NJ, Green CR, Rothery S, Germroth PG, Thompson RP 1993 The spatial distribution and relative abundance of gap junctional connexin40 and connexin 43 correlate to functional properties of the components of the atrial ventricular conduction system. J Cell Sci 105:985-991

22. Bastide B, Neyses L, Ganten D, Paul M, Willecke K, Traub O 1993 Gap junction protein connexin 40 is preferentially expressed in vascular endothelium and conductive bundles of rat myocardium and is increased under hypertensive conditions. Circ Res 73:1138-1149

23. Bruzzone R, Haefliger JA, Gimlich RL, Paul DL 1993 Connexin40, a component of gap junctions in vascular endothelium, is restricted in its ability to interact with other connexins. Mol Biol Cell 4:7-20

24. Gros D, Jarry-Guichard T, Ten Velde I, de Maziere A, van Kempen MJA, Davoust J, Briand JP, Moorman AFM, Jongsma HJ 1994 Restricted distribution of connexin 40, a gap junctional protein, in mammalian heart. Circ Res 74:839-851

25. Davis LM, Kanter HL, Beyer EC, Saffitz JE 1994 Distinct gap junction protein phenotypes in cardiac tissues with disparate conduction properties. J Am Coll Cardiol 24:1124-1132 